Article

\title{
Agricultural Workforce Crisis in Light of the COVID-19 Pandemic
}

\author{
Dionysis Bochtis $\left.{ }^{1, *} \mathbb{(}\right)$, Lefteris Benos ${ }^{1}$, Maria Lampridi ${ }^{1}\left(\mathbb{0}\right.$, Vasso Marinoudi ${ }^{2}$, \\ Simon Pearson ${ }^{2}$ and Claus G. Sørensen ${ }^{3}$ (D) \\ 1 Institute for Bio-Economy and Agri-Technology (IBO), Centre of Research and Technology-Hellas (CERTH), \\ 6th km Charilaou-Thermi Rd, GR 57001 Thessaloniki, Greece; e.benos@certh.gr (L.B.); \\ m.lampridi@certh.gr (M.L.) \\ 2 Lincoln Institute for Agri-Food Technology (LIAT), University of Lincoln, Lincoln LN6 7TS, UK; \\ vm352@efb.gr (V.M.); SPearson@lincoln.ac.uk (S.P.) \\ 3 Department of Engineering, Aarhus University, DK-8000 Aarhus C, Denmark; claus.soerensen@eng.au.dk \\ * Correspondence: d.bochtis@certh.gr
}

Received: 10 August 2020; Accepted: 1 October 2020; Published: 5 October 2020

\begin{abstract}
COVID-19 and the restrictive measures towards containing the spread of its infections have seriously affected the agricultural workforce and jeopardized food security. The present study aims at assessing the COVID-19 pandemic impacts on agricultural labor and suggesting strategies to mitigate them. To this end, after an introduction to the pandemic background, the negative consequences on agriculture and the existing mitigation policies, risks to the agricultural workers were benchmarked across the United States' Standard Occupational Classification system. The individual tasks associated with each occupation in agricultural production were evaluated on the basis of potential COVID-19 infection risk. As criteria, the most prevalent virus transmission mechanisms were considered, namely the possibility of touching contaminated surfaces and the close proximity of workers. The higher risk occupations within the sector were identified, which facilitates the allocation of worker protection resources to the occupations where they are most needed. In particular, the results demonstrated that $50 \%$ of the agricultural workforce and $54 \%$ of the workers' annual income are at moderate to high risk. As a consequence, a series of control measures need to be adopted so as to enhance the resilience and sustainability of the sector as well as protect farmers including physical distancing, hygiene practices, and personal protection equipment.
\end{abstract}

Keywords: coronavirus; occupational health and safety; food security; resilience; control measures

\section{Introduction}

\subsection{The Pandemic Background}

On 30 January 2020, the World Health Organization (WHO) triggered their highest alert by announcing the coronavirus disease (COVID-19) as a public-health emergency of international concern. On 11 March 2020, COVID-19 was declared a pandemic. As the director-general of WHO explained: "CO stands for corona, VI for virus, D for disease and 19 for the year the outbreak was first identified". COVID-19 is the infectious disease resulting from the severe acute respiratory syndrome coronavirus 2 (SARS-CoV-2) [1]. The virus can be transmitted during close contact between people via small respiratory droplets produced when an infected individual speaks, sneezes, or coughs. Furthermore, these droplets can contaminate surfaces. Common symptoms include dry cough and fever or mild symptoms such as nasal congestion, sore throat, loss of smell or taste as well as toes and fingers discoloration [1]. The virus can be asymptomatic, making COVID-19 control extremely challenging, as 
it can be passed on by individuals who might not notice that they have been infected. At the global level, governments have taken precaution measures to "flatten the curve", such as quarantine, lockdown, the isolation of infected individuals, travel restrictions, border shutdowns and social distancing [2,3]. However, these actions proved to have a detrimental effect on the economy leading to the economic recession and crisis [4].

COVID-19 has severely tested the resilience of supply chains. The effects of COVID-19 on agriculture, as in any sector, have not been manifested in full, while currently a second wave of the virus is impacting many countries. Key impacts on the food system up to now include the general population panic shopping and warehousing of durable food, including pasta, flour, beans and rice [5]. This led to empty shelves at supermarkets. Afraid of running out of domestic supplies, some countries were cautious and decided to close their borders. For example, Russia, Kazakhstan and Serbia temporarily banned exports of key staple foods [6,7]. In the same vein, European Union (EU) countries, such as France, suggested closing the borders of Europe until October 2020 [8]. According to the Food and Agricultural Organization of the United Nations (FAO), from the beginning of May (2020), the international prices of the major staple commodities, such as wheat and maize have dropped. Conversely, rice is the only staple product whose price has risen. This is attributed to export restrictions of Vietnam, which is a key supplier, until 1 May 2020 [9]. On the other hand, great disturbance of supply chains as a consequence of population "lockdowns" has provoked a global decline in demand across the food service sector, such as restaurants, open markets, catering and hotels [10]. Effective closure of food service segments has impacted all businesses across the supply chain including farms which provide the primary produce. To make matters worse, transport restrictions have hindered farmers' and fishers' ability to access markets, hence, limiting their productive capacities [9]. Disturbances downstream from farms can also cause accumulative surpluses, putting extra pressure on storage facilities, especially for highly perishable commodities.

\subsection{Pandemic Effects on Agriculutral Sector}

COVID-19 has impacted the agricultural workforce, especially the pool of seasonal agricultural workers. These are often migrant workers, typically employed in the crop harvesting, who use highly dexterous and physical skills [11,12]. Lockdowns and restrictions in the mobility of workers across borders contributed to labor shortages, mainly in countries that rely on seasonal workers. However, the ability of an agricultural system to exploit workers that can travel between workplaces constitutes a fundamental condition for its sustainability [13]. Unfortunately, emergency travel bans considerably decreased the available workforce. Moreover, no certainty exists that seasonal workers would like to work in countries that have been infected by COVID-19. Additionally, it was noted that many native workers fell ill or took care of sick members of the family or children, due to the closing of schools, further impacting the availability of seasonal personnel [14]. These consequences have particularly affected vegetable and fruit producers as well as garden nurseries and horticulture [15]. However, for many crops, the harvesting season is fixed and a deficiency of labor can result in production shortages in the food market and higher prices, making markets even more unforeseeable [16].

Owing to disruptions in logistics and transport services, COVID-19 lockdowns also impacted the provision of key intermediate products for farmers, such as pesticides, fertilizers and seeds. Additional supply chain checks and procedures resulted in delays to the transit of these products. Shortages or high prices in personal protection equipment from COVID-19 infection, such as hand sanitizers and face masks, caused additional delays and problems [5]. A representative example was China, where pesticide production declined suddenly after production plants shut down. Delays to the transport of these intermediate products can disturb supply chains for extended periods from 2020 and beyond [17].

In a nutshell, lockdown measures to contain the spread of COVID-19 caused a cascading effect on agricultural supply chains, especially of perishable products. In particular, a considerable decline in labor productivity, higher labor and transport costs, substantial income losses for farmers, food shortages and an increase in perishable products' prices, like vegetables and fruits for consumers, was 
observed during the first weeks [8]. As a means to document the existing situation in the agricultural sector, predicting the potential effects of the COVID-19 pandemic and suggesting measures to mitigate them, several studies have been conducted. Some of them analyzed solely the impact of the virus on agricultural production regarding the first infected by COVID-19 countries, namely China $[18,19]$ and later Italy [7,20-22]. In contrast, some studies dealt with the agricultural sector of countries, which were later infected by the viral pandemic, including countries from the rest of Asia (India [23,24] and Iran [25]), Oceania (Australia [26] and New Zealand [27]), Europe (rest of EU [5,28] and the United Kingdom (UK) [29]) as well as America (Argentine [30], Peru [31], Canada [32-36] and the US $[14,37,38])$.

\subsection{Policy Approaches to Mitigate the Negative Consequences of the COVID-19 Pandemic on Agriculture}

Undoubtedly, the agricultural sector is one of the most precarious and unforeseeable sectors. This fact has become even more intense because of the COVID-19 pandemic outbreak. The major short-term concern was to keep farmworkers healthy. For this purpose, farmers, like the entire society, coped with unprecedented measures in order to contain the virus' spread. In a few words, precaution interventions, such as social distancing, travel restrictions, lockdown and self-isolation, proved to have a cascade effect on agriculture, introducing major limitations for farmworkers that have led to potentially devastating consequences. In the aftermath of these measures, the mobility of seasonal workers, especially that of migrant ones, was highly restricted, resulting in delays in harvesting and increased food losses, mostly affecting perishable goods. The governments of developed countries, including the US, UK, France, Germany, Spain and Italy, which highly rely on this labor force, urgently adopted strategies to avoid disturbances owing to the imminent labor shortage. Overall, these strategies seem to be altered from one day to another, mirroring the problem's depth.

In the EU, for example, the policies for mitigating the seasonal workers shortage amid the harvesting period can be briefly analyzed into four axes according to the study of Mitaritonna and Ragot [8]:

- Substituting seasonal migrant labor with domestic workers: websites were created to put unemployed individuals and part-time workers in touch with farmers. As a means to encourage this policy, the workers could combine unemployment benefits with the agricultural wage. Although this measure seemed to be successful at the first stage, attracting a plethora of applicants, the recruitment rates were very low, as the applicants wanted to return to their jobs as soon as possible. In addition to this, extra training costs arose, given that there was an important mismatch of the required skills.

- Applying deviations from labor laws so as to allow agricultural workers to work more: for instance, in France, workers were allowed to work also on Sundays and for more hours. In return, the hours worked further than a defined threshold were paid as overtime.

- Implementing very strict health measures during the reception of the seasonal migrant workers: to that end, seasonal migrants could enter Germany, for example, exclusively by plane and only when they were tested for COVID-19. Afterwards, for the first two weeks they should live and work separately from the other workers. Nevertheless, taking into account the high rates of COVID-19 cases in Europe, they faced the reasonable workers' fear of being infected by the virus if they came to work.

- Regularizing irregular migrants: even though the exact number of them is hard to assess, irregular migrants are working in the agricultural sector. Their assistance in such a labor shortage crisis would definitely be beneficial. However, this constitutes a controversial approach, particularly for countries having very restrictive migration policies.

The aforementioned strategies can help in the emergency situation characterized by a shortage of workers. It is very hard to single out which policy is the most effective, that is to say which combines the overcoming labor shortage with the lower costs. 
Another important aspect is that health should be guaranteed throughout the food chain. To achieve this goal, measures like establishing biosecurity arrangements, enacting stricter employee health policies, using cashless transactions and gathering and communicating scientific evidence as soon as possible could help [39]. Limiting the COVID-19 spread in workplaces is another major concern. The example of the virus clusters in the meatpacking industry in California [14] reveals that COVID-19 may spread rapidly, thus reducing the availability of workers and leading to possible local lockdowns. More recently, workers from a meat processing industry in Greece [40] contracted COVID-19, with health officials deciding self-isolation for them in their home and closing the company. One solution to eradicate such problems would be working in shifts in order to avoid crowding with fewer people involved in the process by keeping safe distances and using personal protection like face masks, gloves and antiseptics.

\subsection{Aim of the Study}

In total, significant progress has been made in identifying the main problems caused by the first emergency measures to prevent the COVID-19 spread and the subsequent chain reaction in the food stocks, demand and prices. However, it is of major importance to assess the potential consequences of the COVID-19 pandemic on agricultural-related occupations. To our knowledge, no study exists in the relative literature on this topic. Towards this direction, the aim of the present investigation is to examine the above consequences and suggest ways to ensure the smooth operation of the agricultural sector in case of a second wave of COVID-19. To this end, since two clear sources of infection occur pertaining to the virus' transmission, namely the close proximity of workers and contaminated surfaces, the individual tasks (based on US Standard Occupational Classification system-SOC) are assessed with respect to these sources. There is an imperative necessity to manage potential COVID-19 resurgence, to protect workers and their jobs, as well as assure food supply and security.

\section{Materials and Methods}

In the absence of a methodology for such an analysis, a new methodology was developed. To meet this objective, each agricultural occupation was analyzed and characterized based on the individual tasks comprising this occupation and the corresponding potential risks.

For the analysis of the occupations, the employment and salaries data from the US Bureau of Labor Statistics (BLS) were implemented. For the standardization of occupations, the US 2018 Standard Occupational Classification (SOC) system was employed and more specifically, the eight-digit scheme of the Occupational Information Network (O*NET) classification system [41]. Overall, 17 occupations related to agriculture were considered for the current investigation. It should be stressed that the jobs involving aquaculture and logging activities were excluded from the present analysis. The investigated occupations are summarized in Table 1 along with their eight-digit code and the number of tasks they encompass.

In order to assess the effect of the pandemic on the total agricultural workforce and on the total budget allocated to the agricultural occupations' salaries, the distribution of each occupation in the above metrics has to be considered. By processing the data provided by the US Department of Labor statistics (data refer to May 2017), Figure 1a,b presents the annual budget and the workforce distribution among the selected occupations. 
Table 1. The $\mathrm{O}^{*} \mathrm{NET}$ categorization of agricultural occupations and the corresponding codes along with the number of tasks they involve according to [41].

\begin{tabular}{ccc}
\hline 8-Digit O*NET Code & Occupation & No. of Tasks \\
\hline $11-9013.01$ & Nursery and Greenhouse Managers & 20 \\
$11-9013.02$ & Farm and Ranch Managers & 26 \\
$13-1074.00$ & Farm Labor Contractors & 8 \\
$17-2021.00$ & Agricultural Engineers & 13 \\
$19-1011.00$ & Animal Scientists & 9 \\
$19-1013.00$ & Soil and Plant Scientists & 20 \\
$19-4011.01$ & Agricultural Technicians & 25 \\
$19-4011.02$ & Food Science Technicians & 15 \\
$45-1011.07$ & First-Line Supervisors of Agricultural Crop and & 24 \\
$45-1011.08$ & Horticultural Workers & 18 \\
$45-2011.00$ & Cirst-Line Supervisors of Animal Husbandry and Animal & 22 \\
$45-2041.00$ & Care Workers & 5 \\
$45-2091.00$ & Agricultural Inspectors & 17 \\
$45-2092.01$ & Graders and Sorters, Agricultural Products & 21 \\
$45-2092.02$ & Agricultural Equipment Operators & 14 \\
$45-2093.00$ & Nursery Workers & 22 \\
$49-3041.00$ & Farmworkers and Laborers, Crop & 13 \\
\hline
\end{tabular}

With the intention of assessing the risk level of the tasks comprising each occupation, each task was classified with respect to the contamination risk. Four levels of risk were identified, namely: minimal, low, moderate and high, by considering the most prevalent virus transmission mechanisms, namely the proximity of workers and the possibility of touching contaminated surfaces. In brief, a task has:

- Minimal risk - when it does not require the physical presence of the worker in order to be performed. Usually, this level includes office tasks that can be carried out remotely (teleworking potential). Obviously, considering the remote execution of the task, there is no chance of touching contaminated surfaces.

- Low risk-when it requires the physical presence of the worker in the field/office/laboratory. Little contact with other people is required, mostly with the same individuals every day, while there is a little chance of touching contaminated surfaces.

- Moderate risk - when physical human presence is required in the field/office/laboratory. Moderate contact with other people is needed, mostly with the same people every day. Moreover, contact with costumers or workers from different places may be observed, while there is a moderate chance of touching contaminated surfaces.

- High risk-when physical human presence is required in the field/office/laboratory while considerable contact with other people is observed including customers, workers from different places and so on. In addition, there is a high chance of touching contaminated surfaces.

Six assessors, namely the authors of this study, independently assessed the level of risk of each task taking into account their own knowledge and the elaborated knowledge of an interviewed group of agricultural professionals including farm managers, first-line supervisors of crop and animal production, and various agricultural workers on horticulture, nursery, and livestock production. A consensus telemeeting of the assessors was held for the purpose of resolving any disagreement and arriving at the final result. The assessors have proved expertise in various fields of agricultural production including occupational health and safety, automation, operations management, agricultural technologies assessment, and agricultural ergonomics.

As can be seen in Figure 2, for the characterization of each task, the following methodology was implemented. Each individual task of an occupation is uniquely characterized by one of the four 
defined risk levels. To this end, given the four risk levels, (minimal $(j=1)$, low $(j=2)$, moderate $(j=3)$, or high risk level $(j=4))$, for each one of the $n$ defined tasks composing an occupation, the grade " 1 " was assign for the risk level to which the particular task was classified, while the grade " 0 " was assigned for the other three levels. For example, if the first task $(i=1)$ of an hypothetical occupation was characterized as "moderate", then $X_{1,3}=1$ and $X_{1,1}=X_{1,2}=X_{1,4}=0$. After assigning grades to all the tasks of an occupation according to the same procedure, the average grade was calculated providing the percentage of tasks classified at each risk level $\left(w_{j}=\frac{1}{n} \sum_{i=1}^{n} X_{i, j} \cdot 100 \%, j \in[1,2,3,4]\right.$, noting that $\left.\sum_{j=1}^{4} w_{j}=100 \%\right)$. Finally, by considering the above approach, each occupation receives a weighted risk level characterization of the tasks it involves, which can be illustrated in the form of a single bar chart, as can be seen in the right side of Figure 2.

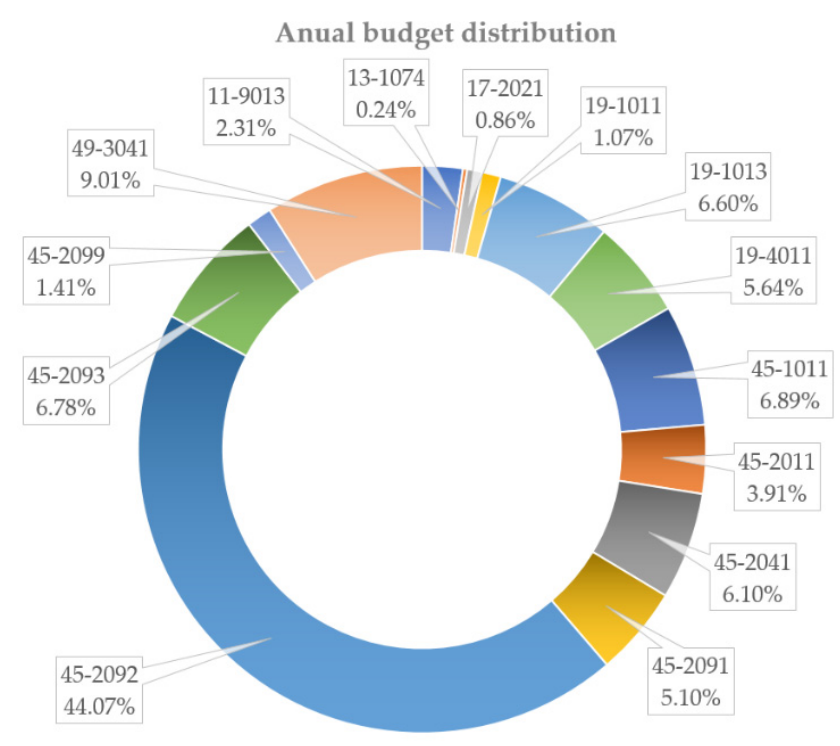

(a)

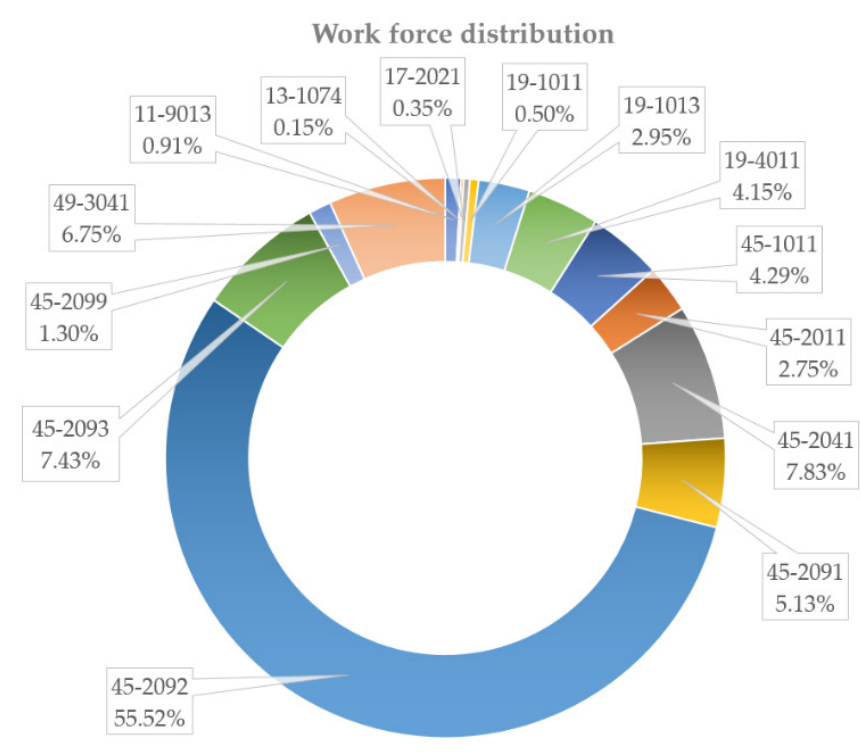

(b)

Figure 1. (a) Annual budget and (b) workforce distribution of agricultural occupations; the correspondence between the codes and occupations is shown in Table 1 . 


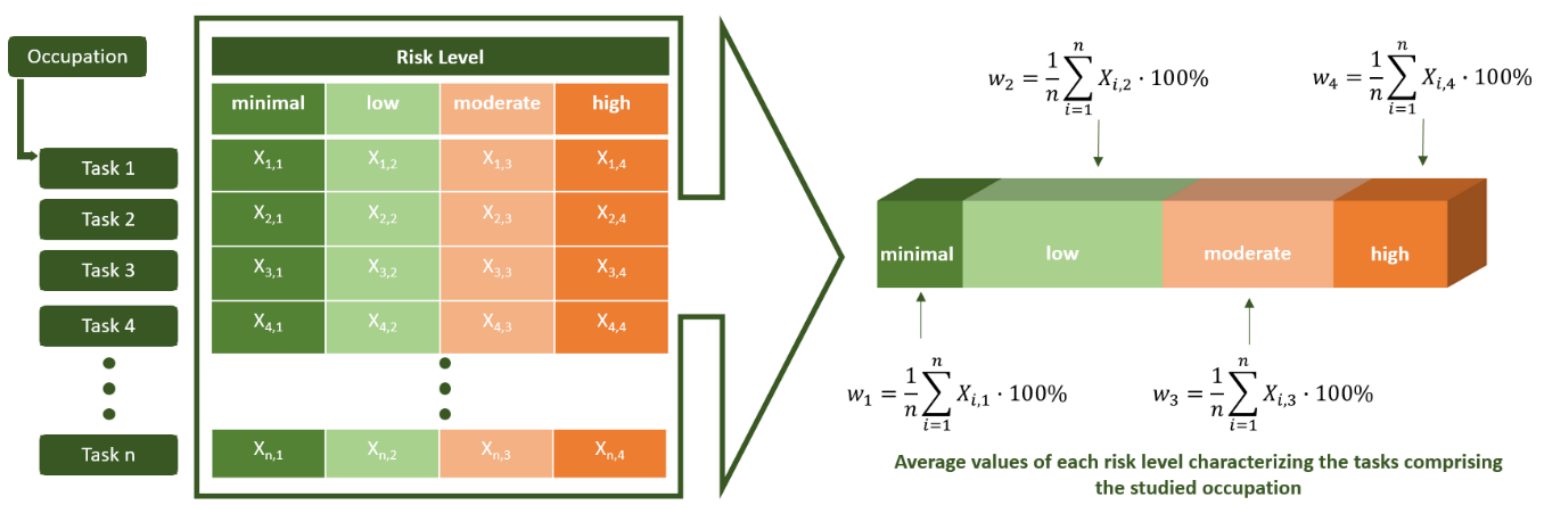

Figure 2. Methodology for the characterization of the risk level of the tasks comprising an occupation.

\section{Results}

\subsection{Contamination Risk Level Distribution in Agricultural Occupations}

The aforementioned methodology was implemented for the 17 occupations including in total 292 individual tasks (an elaborate description of them is provided in [41]), which were assigned to different risk levels in conformity with the proposed methodology described in Section 2. The contamination risk level distribution among all the agricultural occupations is illustrated in Figure 3 . The high risk occupation was shown to be "Graders and Sorters, Agricultural Products" (45-2041.00), whose responsibilities include the activities of grading, sorting and/or classifying agricultural products by condition, weight, size or color, with $20 \%$ of the tasks demonstrating moderate and $80 \%$ of the tasks demonstrating high risk. The next occupation under high risk was "Farm Labor Contractors" (13-1074.00), who have the responsibility of recruiting and hiring seasonal agricultural workers. They may also transport workers to the work sites and provide tools and meals for the workers. This physical interaction engages in a high risk of contamination, either due to close contact with agricultural workers or the high chance of touching contaminated surfaces. In particular, out of the tasks of the above occupation, $63 \%$ were observed to have high risk, $25 \%$ moderate risk, and 13\% low risk, while none of them had minimal risk of being affected by COVID-19.

Vulnerable occupations to the COVID-19 infection, although with lower risk levels, were also observed to be "Farmworkers, Farm and Ranch Animals" (45-2093.00), "Farmworkers and Laborers, Crop" (45-2092.02) and "First-Line Supervisors of Agricultural Crop and Horticultural workers" (45-1011.07). In contrast, the less affected occupations were "Food Science Technicians" (19-4011.02) and "Farm Equipment Mechanics and Service Technicians" (49-3041.00).

It can be deduced that occupations that are mostly related to the scientific aspects of agriculture and management, which can be performed remotely or with little contact with other people, have minimal to low risk of contamination (tasks of minimal and low risk level greater than $50 \%$ of the total number of tasks). On the other hand, occupations that require many people working at the same time together or require meetings with different people have a moderate to high risk of contamination (tasks of moderate and high risk level greater than $50 \%$ of the total number of tasks). 


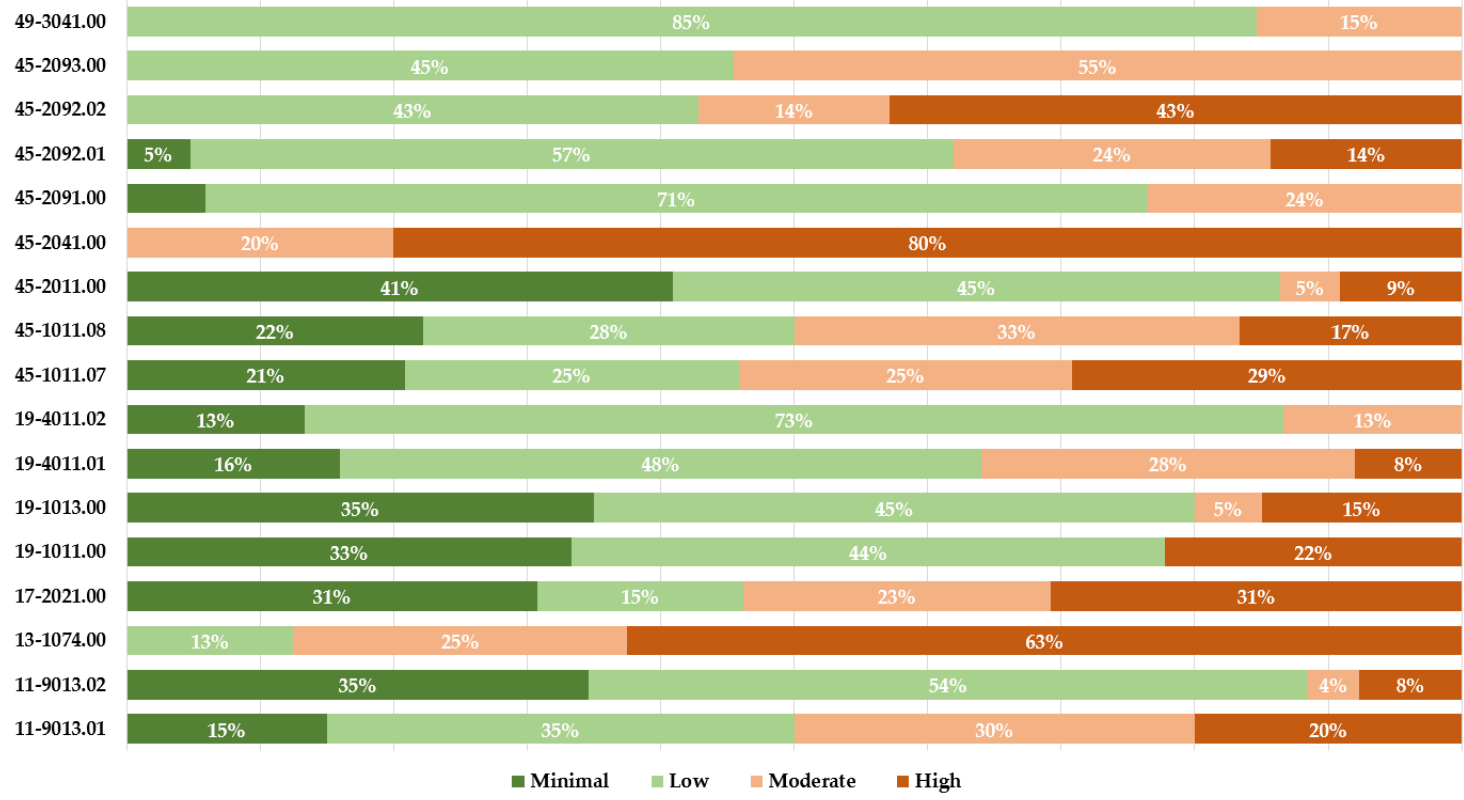

Figure 3. Contamination risk level distribution of each agricultural occupation; the correspondence between the codes and occupations is shown in Table 1.

\subsection{Annual Budget and Total Workforce Effect}

The worker who is classified in a specific occupation devotes a certain number of working hours to the execution of the individual tasks of the work. Therefore, the risk level of losing working hours can also be expressed as the risk level of the entire job position. Consequently, reducing the results to the workforce, it can be inferred (based on the data presented in Figure 1) that $5 \%$ of the total working time of agricultural employees (in the US-based scenario) are at high risk while $45 \%$ at moderate risk (Figure 4a). Cumulatively, 50\% of the agricultural workforce is at moderate to high risk of contracting the disease in their workplace and the corresponding $50 \%$ of workhours are at moderate to high risk of being lost with the eventual consequences to food security and the economy in general. These employees mainly belong in occupations that require many people working at the same time together in close proximity or meeting with different people or/and exchanging tools. These numbers correspond to the $8 \%$ and $46 \%$ of the annual salaries, respectively (Figure $4 \mathrm{~b}$ ), meaning that $54 \%$ of the agricultural annual budget for workers' salaries are at moderate to high risk demonstrating the level of economic insecurity that is related to the pandemic. In contrast, $31 \%$ of the workforce time and $27 \%$ of the annual income are not expected to be influenced by the pandemic, while $19 \%$ of the workforce and annual salaries are at low risk. 


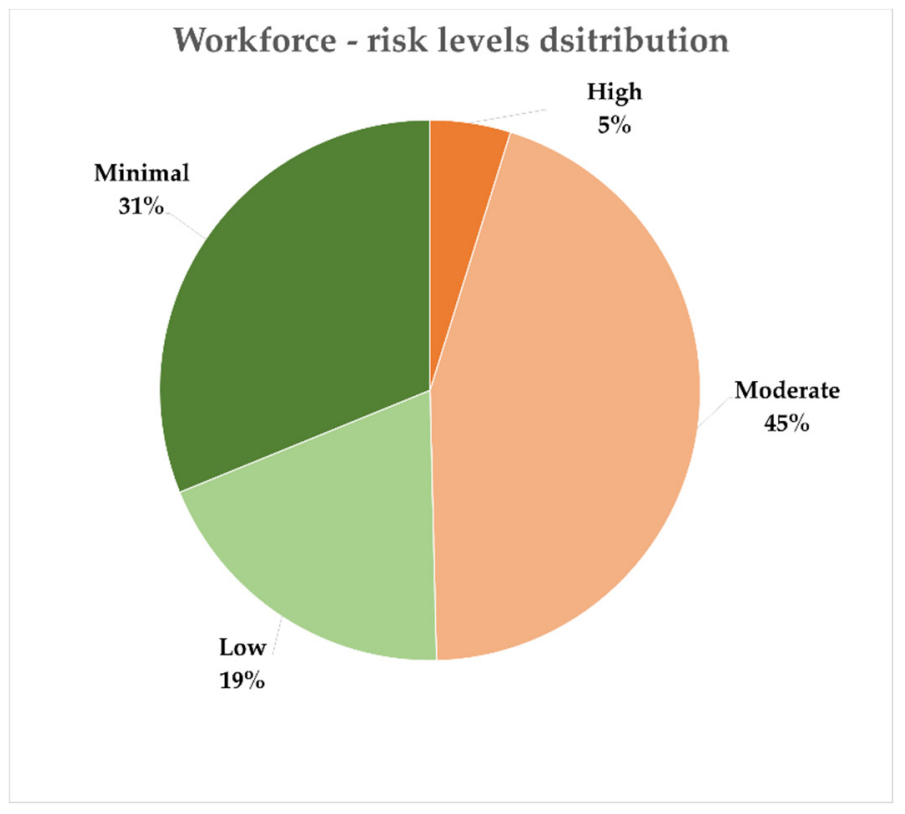

(a)

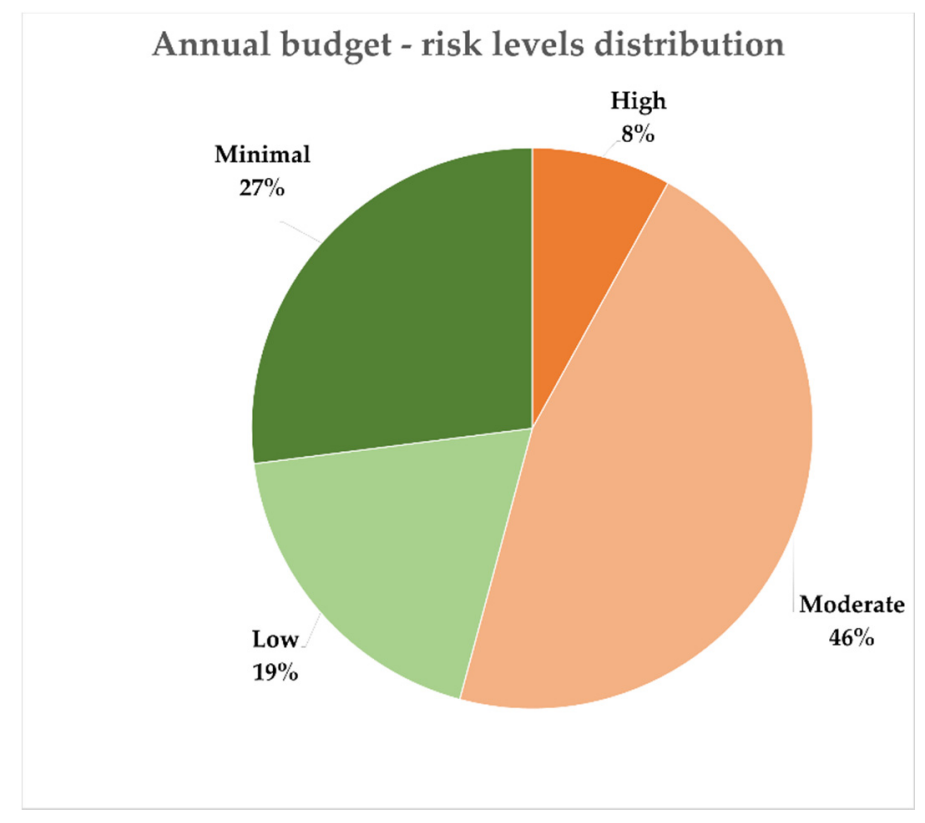

(b)

Figure 4. Risk level distribution in (a) the workforce and (b) the annual budget.

\section{Discussion and Conclusions}

With the object of assessing the potential impact of the consequences of the COVID-19 pandemic on the agricultural workforce, the well-defined US SOC system was used. In the absence of an existing methodology, the tasks of all SOC occupations were characterized as having minimal, low, moderate or a high risk level of getting the virus. The preliminary results of this study revealed the gravity of the matter, especially for workers of the "Farming, Fishing and Forestry" (45-0000) occupations major group, who work in close proximity conditions. On the other hand, "Management" (11-0000) and "Life, Physical and Social Science" (19-0000)-related occupations present lower risk, as a considerable part of their tasks can be performed remotely. In total, $31 \%$ of the workforce in agricultural occupations and $27 \%$ of the corresponding annual budget are not anticipated to be affected by COVID-19, while 
$19 \%$ of the workforce and corresponding budget are at low risk. However, it was found that $50 \%$ of the agricultural workforce and the $54 \%$ of the corresponding salaries are at moderate to high risk, hence, indicating the economic uncertainty associated with the current pandemic.

The adoption of a series of measures that can increase the resilience and sustainability of the sector in such urgent situations are imperative. These measures include different strategies to find seasonal workers, such as substituting seasonal migrant labor with domestic workers, applying deviations from labor laws, implementing very strict health measures during the reception of seasonal migrant workers and regularizing irregular migrants [8]. Another way for the mitigation of the existing problems is to facilitate the transfer of perishable products and logistics by avoiding trade restriction and minimizing trade costs. This would contribute to decrease the food loss. Moreover, facilitating border procedures in essential inputs such as fertilizers, veterinary medicines and pesticides by allowing for digital copies of certificates, for instance, could be beneficial. It would be also very consequential to maintain international markets open and transparent. Transparency can be accomplished through timely market information, which stands for information sharing. As a consequence, panic buying can be alleviated and trust among markets and countries be assured.

As far as the precaution measures pertaining to the spread of the coronavirus are concerned, the policies also implemented in other sectors have already been adopted [42,43]. In summary, control measures to protect workers against COVID-19 on farms include:

- Physical distancing: (a) the limitation of close contact by ensuring a $2 \mathrm{~m}$ minimum distance. This distance must also be kept during breaks; (b) the limitation of the number of people working together in one workspace, especially the closed ones like greenhouses, by working in shifts; (c) installing signage for maintaining physical distancing; (d) the use of alternative ways of communication, such as teleconferences and emails instead of face-to-face meetings. If it is necessary, meeting in outdoor spaces is highly recommended; and (e) if social distancing cannot be maintained, face masks must be worn, while their usage, taking off and disposal must follow all the instructions of WHO [44].

- Hygiene practices: (a) all workers should know how to properly wash their hands as well as avoid touching their mouth and nose. Moreover, a personal hand sanitizer should be provided to all workers to prevent the multiple usage of a single one. Frequent hand washing should be encouraged before entering the farm, before and after breaks, or after contact with surfaces and other people; (b) all non-essential visitors must be kept off the farm. Essential visitors, such as those needed for the care of the cleaning facilities and animals, must follow all the above practices concerning both physical distancing and good hygiene. Moreover, visitors should avoid visiting the same washroom facilities with the farm employees; (c) handling packages received at the farm must be left untouched for quite some time or disinfected in order to reduce the possibility of the virus being present on the surfaces; (d) the cleaning frequency of commonly touched surfaces and areas, like machinery, workstations, farm equipment and washrooms, must be increased; and (e) wherever possible, each worker should use their own tool, tractor, etc.

- Other precaution measures: (a) pre-authorizing farm visitors; (b) regularly checking workers for signs of COVID-19, such as shortness of breath, coughing and/or fever. In case someone has any symptom, they must self-isolate and notify their supervisor as soon as possible to call a doctor and provide the COVID-19 testing. If the workers test positive, all the other employees that work in the same environment or came into contact with them must be quarantined. Immediately after, COVID-19 test must also be provided for them in order to protect their families; (b) with the object of restricting the COVID-19 pandemic spread, the farms, as far as possible, need to be isolated so as to minimize the number of infected cases in case of someone contracting COVID-19; (c) farm employers and supervisors must be kept informed, and train workers about how to protect themselves from the coronavirus, well communicating the required measures, and following all national health warning recommendations associated with the COVID-19 pandemic. 
The precaution measures are likely to be resorted, considering the precariousness about imminent waves of COVID-19. This pandemic, however, is an opportunity to create a fertile ground for the coordinated efforts of researchers, agricultural practitioners, infectious disease specialists and policymakers. It is anticipated that this preliminary study can serve as a basis for future research concerning integrated strategies for ensuring the smooth operation of the food supply chain, occupational health and jobs' protection.

Author Contributions: Conceptualization, L.B. and D.B.; methodology, L.B., M.L., D.B. and V.M.; investigation, L.B., V.M. and M.L.; writing - original draft preparation, L.B., M.L. and D.B.; writing —review and editing, S.P., C.G.S., and D.B.; visualization, L.B., M.L. and V.M.; supervision, S.M., C.G.S. and D.B. All authors have read and agreed to the published version of the manuscript.

Funding: This research received no external funding.

Conflicts of Interest: The authors declare no conflict of interest.

\section{References}

1. Q\&A on Coronaviruses (COVID-19). Available online: https://www.who.int/emergencies/diseases/novel-cor onavirus-2019/question-and-answers-hub/q-a-detail/q-a-coronaviruses (accessed on 3 August 2020).

2. WHO Situation Report-44. Available online: https://www.who.int/docs/default-source/coronaviruse/\%0Asi tuation-reports/20200304-sitrep-44-covid-19.pdf?sfvrsn=783b4c9d_2 (accessed on 3 August 2020).

3. Coronavirus: Travel Restrictions, Border Shutdowns by Country | Coronavirus Pandemic News | Al Jazeera. Available online: https:/www.aljazeera.com/news/2020/03/coronavirus-travel-restrictions-border-shutdown s-country-200318091505922.html (accessed on 3 August 2020).

4. Nicola, M.; Alsafi, Z.; Sohrabi, C.; Kerwan, A.; Al-Jabir, A.; Iosifidis, C.; Agha, M.; Agha, R. The socio-economic implications of the coronavirus pandemic (COVID-19): A review. Int. J. Surg. 2020, 78, 185-193. [CrossRef] [PubMed]

5. Jámbor, A.; Czine, P.; Balogh, P. The Impact of the Coronavirus on Agriculture: First Evidence Based on Global Newspapers. Sustainability 2020, 12, 4535. [CrossRef]

6. Russia Wants to Limit Grain Exports to Protect Food Supplies-Bloomberg. Available online: https://ww w.bloomberg.com/news/articles/2020-03-27/wheat-futures-rise-as-russia-considers-grain-export-quota (accessed on 6 August 2020).

7. Pulighe, G.; Lupia, F. Food First: COVID-19 Outbreak and Cities Lockdown a Booster for a Wider Vision on Urban Agriculture. Sustainability 2020, 12, 5012. [CrossRef]

8. Mitaritonna, C.; Ragot, L. After Covid-19, Will Seasonal Migrant Agricultural Workers in Europe Be Replaced by Robots? CEPII Policy Brief No. 33. 2020. Available online: http://www.cepii.fr/CEPII/en/publications/pb/ abstract.asp?NoDoc=12680 (accessed on 3 October 2020).

9. Q\&A: COVID-19 Pandemic-Impact on Food and Agriculture | FAO | Food and Agriculture Organization of the United Nations. Available online: http://www.fao.org/2019-ncov/q-and-a/impact-on-food-and-agricultu re/en/ (accessed on 4 August 2020).

10. Prices of Agricultural Commodities Drop 20\% Post COVID-19 Outbreak-Rediff Realtime News. Available online: https://realtime.rediff.com/news/india/Prices-of-agricultural-commodities-drop-20-post-C OVID19-outbreak/955078599584b749?src=interim_alsoreadimage (accessed on 3 August 2020).

11. Benos, L.; Tsaopoulos, D.; Bochtis, D. A Review on Ergonomics in Agriculture. Part I: Manual Operations. Appl. Sci. 2020, 10, 1905. [CrossRef]

12. Benos, L.; Tsaopoulos, D.; Bochtis, D. A Review on Ergonomics in Agriculture. Part II: Mechanized Operations. Appl. Sci. 2020, 10, 3484. [CrossRef]

13. Lampridi, M.; Sørensen, C.; Bochtis, D. Agricultural Sustainability: A Review of Concepts and Methods. Sustainability 2019, 11, 5120. [CrossRef]

14. Martin, P. COVID-19 and California farm labor. Calif. Agric. 2020, 74, 67-68. [CrossRef]

15. OECD Fruit and Vegetables Scheme-OECD Fruit and Vegetables Scheme. Available online: https: //www.oecd.org/agriculture/fruit-vegetables/ (accessed on 3 August 2020). 
16. Seasonal Workers, CAP and COVID-19, Farm to Fork-EURACTIV.com. Available online: https://www.eu ractiv.com/section/agriculture-food/news/seasonal-workers-cap-and-covid-19-farm-to-fork/ (accessed on 4 August 2020).

17. COVID-19: Channels of Transmission to Food and Agriculture; FAO: Rome, Italy, 2020.

18. $\mathrm{Pu}, \mathrm{M}$.; Zhong, Y. Rising concerns over agricultural production as COVID-19 spreads: Lessons from China. Glob. Food Sec. 2020, 26, 100409. [CrossRef]

19. Zhang, S.; Wang, S.; Yuan, L.; Liu, X.; Gong, B. The impact of epidemics on agricultural production and forecast of COVID-19. China Agric. Econ. Rev. 2020. [CrossRef]

20. Cortignani, R.; Carulli, G.; Dono, G. COVID-19 and labour in agriculture: Economic and productive impacts in an agricultural area of the Mediterranean. Ital. J. Agron. 2020, 15, 172-181.

21. Barcaccia, G.; D'Agostino, V.; Zotti, A.; Cozzi, B. Impact of the SARS-CoV-2 on the Italian Agri-Food Sector: An Analysis of the Quarter of Pandemic Lockdown and Clues for a Socio-Economic and Territorial Restart. Sustainability 2020, 12, 5651. [CrossRef]

22. Cattivelli, V.; Rusciano, V. Social Innovation and Food Provisioning during Covid-19: The Case of Urban-Rural Initiatives in the Province of Naples. Sustainability 2020, 12, 4444. [CrossRef]

23. McDonald, A.J.; Balwinder-Singh; Jat, M.L.; Craufurd, P.; Hellin, J.; Hung, N.V.; Keil, A.; Kishore, A.; Kumar, V.; McCarty, J.L.; et al. Indian agriculture, air pollution, and public health in the age of COVID. World Dev. 2020, 135, 105064. [CrossRef] [PubMed]

24. Kumar, A.; Padhee, A.K.; Kumar, S. How Indian agriculture should change after COVID-19. Food Secur. 2020, 135, 1-4.

25. Zarei, M.; Rad, A. Covid-19, Challenges and Recommendations in Agriculture. J. Bot. Res. 2020, 2. [CrossRef]

26. Henry, R. Innovations in Agriculture and Food Supply in Response to the COVID-19 Pandemic. Mol. Plant 2020, 13, 1095-1097. [CrossRef]

27. Neef, A. Legal and social protection for migrant farm workers: Lessons from COVID-19. Agric. Human Values 2020, 37, 641-642. [CrossRef]

28. Darnhofer, I. Farm resilience in the face of the unexpected: Lessons from the COVID-19 pandemic. Agric. Human Values 2020, 1, 3.

29. Phillipson, J.; Gorton, M.; Turner, R.; Shucksmith, M.; Aitken-McDermott, K.; Areal, F.; Cowie, P.; Hubbard, C.; Maioli, S.; McAreavey, R.; et al. The COVID-19 pandemic and its implications for rural economies. Sustainability 2020, 12, 3973. [CrossRef]

30. Villulla, J.M. COVID-19 in Argentine agriculture: Global threats, local contradictions and possible responses. Agric. Human Values 2020, 1, 1.

31. Siche, R. What is the impact of COVID-19 disease on agriculture? Sci. Agropecu. 2020, 11, 3-9. [CrossRef]

32. Barichello, R. The COVID-19 pandemic: Anticipating its effects on Canada's agricultural trade. Can. J. Agric. Econ. Can. d'agroeconomie 2020, 68, 219-224. [CrossRef]

33. Brewin, D.G. The impact of COVID-19 on the grains and oilseeds sector. Can. J. Agric. Econ. Can. d'agroeconomie 2020, 68, 185-188. [CrossRef]

34. Cranfield, J.A.L. Framing consumer food demand responses in a viral pandemic. Can. J. Agric. Econ. Can. d'agroeconomie 2020, 68, 151-156. [CrossRef]

35. Deaton, B.J.; Deaton, B.J. Food security and Canada's agricultural system challenged by COVID-19. Can. J. Agric. Econ. Can. d'agroeconomie 2020, 68, 143-149. [CrossRef]

36. Richards, T.J.; Rickard, B. COVID-19 impact on fruit and vegetable markets. Can. J. Agric. Econ. Can. d'agroeconomie 2020, 68, 189-194. [CrossRef]

37. Gunther, A. COVID-19: Fight or flight. Agric. Human Values 2020, 1, 1.

38. Lal, R. Home gardening and urban agriculture for advancing food and nutritional security in response to the COVID-19 pandemic. Food Secur. 2020, 12, 1-6. [CrossRef]

39. COVID-19 and the Food and Agriculture Sector: Issues and Policy Responses. Available online: http://www.oecd.org/coronavirus/policy-responses/covid-19-and-the-food-and-agriculture-sector-issuesand-policy-responses-a23f764b/ (accessed on 7 August 2020).

40. Over 100 New Cases of Covid-19 Signals Critical Point in Greece I GreekReporter.com. Available online: https://greece.greekreporter.com/2020/08/01/over-100-new-cases-of-covid-19-signals-criti cal-point-in-greece/ (accessed on 7 August 2020). 
41. Standard Occupational Classification (SOC) System. Available online: https://www.bls.gov/soc/ (accessed on 5 August 2020).

42. 10 Measures to Protect Against COVID-19 on Farms | The Pig Site. Available online: https://thepigsite.com/a rticles/10-measures-to-protect-against-covid-19-on-farms (accessed on 28 August 2020).

43. COVID-19 Guidance for Farms \& Markets | Pasa Sustainable Agriculture. Available online: https://pasafarm ing.org/covid19/ (accessed on 28 August 2020).

44. When and How to Use Masks. Available online: https://www.who.int/emergencies/diseases/novel-coron avirus-2019/advice-for-public/when-and-how-to-use-masks?gclid=Cj0KCQjw1qL6BRCmARIsADV9Jt ao6SCtOBozLUQrHzRRdPAH82L-SMFmQ0rHxRYMxrHKtHvIUCD845IaAusJEALw_wcB (accessed on 28 August 2020).

C 2020 by the authors. Licensee MDPI, Basel, Switzerland. This article is an open access article distributed under the terms and conditions of the Creative Commons Attribution (CC BY) license (http://creativecommons.org/licenses/by/4.0/). 